\title{
Fabrication methods of the polygonal masonry of large tightly fitted stone blocks with curved surface interfaces in megalithic structures of Peru
}

\author{
Rostislav V. Lapshin, Ph. D. \\ Institute of Physical Problems \\ Zelenograd, Russian Federation \\ E-mail: rlapshin@gmail.com
}

The article suggests methods that allow creating the most complicated type of polygonal masonry found in Peru. This masonry consists of large stone blocks weighing from several hundred kilograms to several tons fitted close to each other almost without a gap between complicated curved surfaces of large area. The work provides a description of techniques, which apparently were used by builders who arrived from Europe. The techniques under discussion are based on the use of a reduced clay model, 3D-pantograph and replicas. The use of a reduced clay model and a pantograph provides not only the unique appearance and high quality of masonry with large blocks, but also allows to significantly increase the productivity of the builders. As machines copying three-dimensional objects are known since the 18th century, the stone structures under consideration should be dated by that and later time. The remaining simpler types of polygonal masonry with smaller stones or fitted surfaces are almost flat, or stones contact with each other by a small area, or there are significant gaps between stones, are quite consistent with the well-known methods of stone processing of those and earlier years, and, therefore, they do not require any additional explanations.

The material was firstly published on April 11, 2021 in the author's blog.

Key words: stone block, polygonal masonry, clay model, pantograph, replica, chisel, hammer, megalith, Inca, Cusco, Ollantaytambo, Machu Picchu, Peru

\section{Copyright (C) 2021 R. V. Lapshin, published under Creative Commons Attribution}

\section{Introduction}

Polygonal masonry is a type of masonry made of natural stone. Stones having an initially arbitrary shape are processed in such a way that form irregular polygons tightly adjacent to each other on the front side of the structure. It should be noted that the name "polygonal masonry" is largely conditional. The fact is that there are many structures classified as polygonal in which stone "polygons" have curved sections besides the linear ones. A feature of the polygonal masonry is that it does not require a building mortar (dry masonry). The polygonal masonry possesses sufficient strength and stability to withstand moderate earthquakes.

In the present paper, a polygonal masonry in the megalithic structures located on the territory of modern Peru is under consideration. The main attention is paid to the masonry consisting of large stone blocks weighing from several hundred kilograms to several tons fitted close to each other almost without a gap between curved surfaces of large area. The remaining simpler types of polygonal masonry, when the stones are small or the mating surfaces are almost flat, or the stones contact each other over a small area, or there are significant gaps between the stones, are quite consistent with the well-known since the ancient times methods of stone processing and, therefore, do not require any special explanation.

In general, a polygonal masonry is not something unprecedented, such masonry has been known in Europe since antiquity. In the Peruvian version, only the quality of the curved interfaces is striking, which is not easy to repeat even in our time. The methods suggested by both the scientific community ${ }^{1,2,3}$ and the enthusiasts ${ }^{4,5,6}$ for fabrication of the Peruvian polygonal masonry do not explain all the observed features and are often far from a reality.

If we look at the shape of the stones in the masonry closely, at the sites of their almost perfect fitting, then there is a feeling that the stones were not processed mechanically but were sculpted. In this regard, many researchers mistakenly decided that the stones were sculpted or cast from a certain plastic mixture - artificial granite, concrete, lime, rock softened by heating, and so on. ${ }^{5,6}$ In this regard, the question immediately arises: why produce an expensive plastic 


\section{Fabrication methods of the polygonal masonry in megalithic structures of Peru}

mixture when there is a lot of ready-to-use material around - natural stone of arbitrary shape? What is even more unclear is: why should plastic mixture be given such complex shapes? Why not make a limited range of standard concrete blocks with locking elements, for example?

There are other arguments against the plastic version. For example, the backside of many blocks is a ragged stone, there is no plastic mixture flowed into the interblock spaces inside the masonry, the stone blocks have veinlets and other features inherent in natural stone; the complex shapes and high curvatures of the interface profiles of neighboring blocks typical of the plastic technology are not observed; the upper free edge of the masonry in the last course of allegedly concrete blocks (Sacsayhuaman) is for some reason ragged and out-of-level, etc. ${ }^{7}$

The methods of polygonal masonry fabrication proposed by the author are based on the use of a reduced clay model, a 3D-pantograph, ${ }^{8}$ and replicas ${ }^{1}$. The main tools for stone processing are a hammer and a steel chisel (a set of chisels). The use of the reduced clay model and the pantograph provides not only the unique appearance and high quality of masonry of large blocks, but also allows to significantly increase the productivity of the builders. Only due to the high productivity it became possible to carry out the volumes of the polygonal construction revealed in Peru for a reasonable time, engaging a reasonable amount of labor force. As machines copying three-dimensional objects are known since the 18th century, the polygonal structures under consideration should be dated beginning from that time.

Since to the moment of the South America conquest by Europeans, the Indians did not know neither iron tools nor wheel, and did not have draft animals, the structures under consideration could only be erected by the builders who come from Europe. Unlike the Indians, these builders had all the necessary tools, mechanisms, and skills for the large-scale construction. The marks of this large-scale stone construction are visible everywhere - Catholic cathedrals, monasteries, palaces, villas, and a lot of urban and industrial buildings. Any large-scale construction always implies the existence of an economy corresponding to this scale. Therefore, the article additionally explains what the economy of Peru was based on in those years.

\section{Methods of fabrication of the polygonal masonry}

\subsection{Clay model shape transfer to a stone billet by means of a pantograph}

First, in accordance with a sketch, the clay model of a structure is made in a reduced scale which blocks form a polygonal masonry. Let us assume for a certainty that the structure is just a wall. Small polygonal blocks of the planned shape are sculpted from clay. The size of these blocks correspond to the size, say, of a basketball or so. The interface between the fitted surfaces is formed by pressing the blocks into each other.

The model of the wall is assembled from the raw model blocks. During the assembly, some material is laid between the blocks that prevents the blocks from sticking to each other during the drying-solidification process. To reduce the influence of the shrinkage effect, the bottom course is dried first, then the next course, and so on. If necessary, the wall is given the required slope. During the drying shrinkage process, the model blocks are matched more closely under their own weight and with small corrections of the builder.

After the solidification of the model of the wall, it is disassembled. Now the "magic" began. The Medieval European builders transferred the surface topography from a small model clay block to a large stone billet of suitable sizes and shape with a specified scale using a 3D-pantograph, ${ }^{8}$ a hammer, and a steel chisel.

The pantograph is a simple lever device based on a parallelogram mechanism. A 2Dpantograph allows to proportionally enlarge/reduce a flat drawing. ${ }^{9}$ Being a logical advancement of the 2D-pantograph, a more complicated 3D-pantograph ${ }^{10}$ (see Fig. 1) allows to proportionally enlarge/reduce a space figure, for example, a statue. In our case, using the 3D-pantograph, the enlarged copy of a small clay model of the block is obtained by processing the stone billet with a hammer and a chisel. 


\section{R. V. Lapshin}

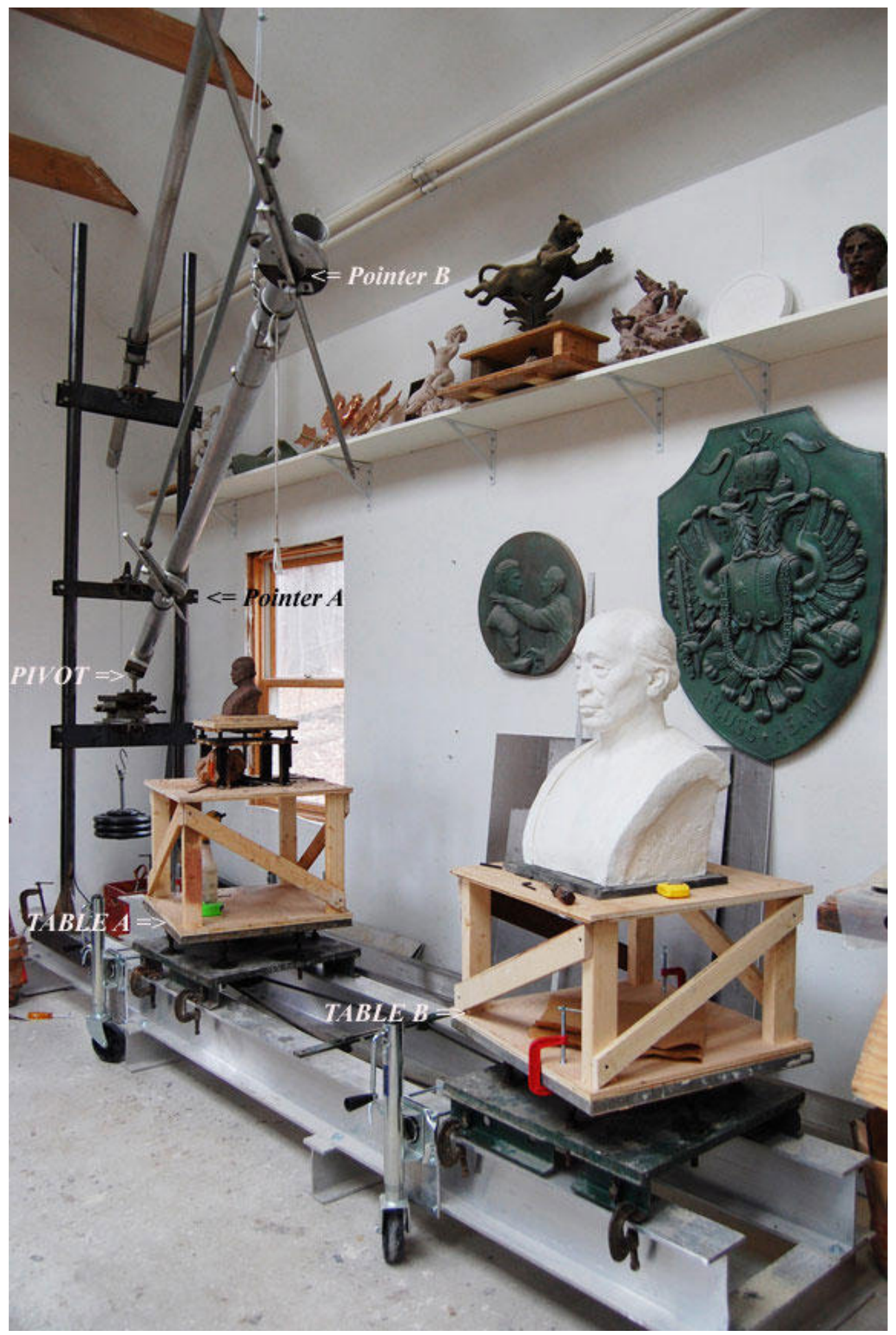

Fig. 1. Modern 3D-pantograph (photo by M. Keropian)

The parallelogram mechanism is located on a boom of the 3D-pantograph. The boom is attached to the frame using a ball joint (see Pivot in Fig. 1). The boom has a counterweight. A sharp probe is fixed on one arm of the parallelogram mechanism (Pointer $A$ ), on the other - a pointer (a part actually similar to the probe; Pointer B in Fig. 1). If someone touches the clay model with a probe, the pointer will show where the corresponding point of the enlarged copy is located in space. The enlargement coefficient is set by the appropriate adjustment of the arms of the lever system. The model and its enlarged copy are located each on their rotary platform (Table A and Table B, respectively). Due to a chain transmission, the platforms can be synchronously rotated around their vertical axes, putting different sides of the 3D-object (model/copy) under the probe/pointer. 


\section{Fabrication methods of the polygonal masonry in megalithic structures of Peru}

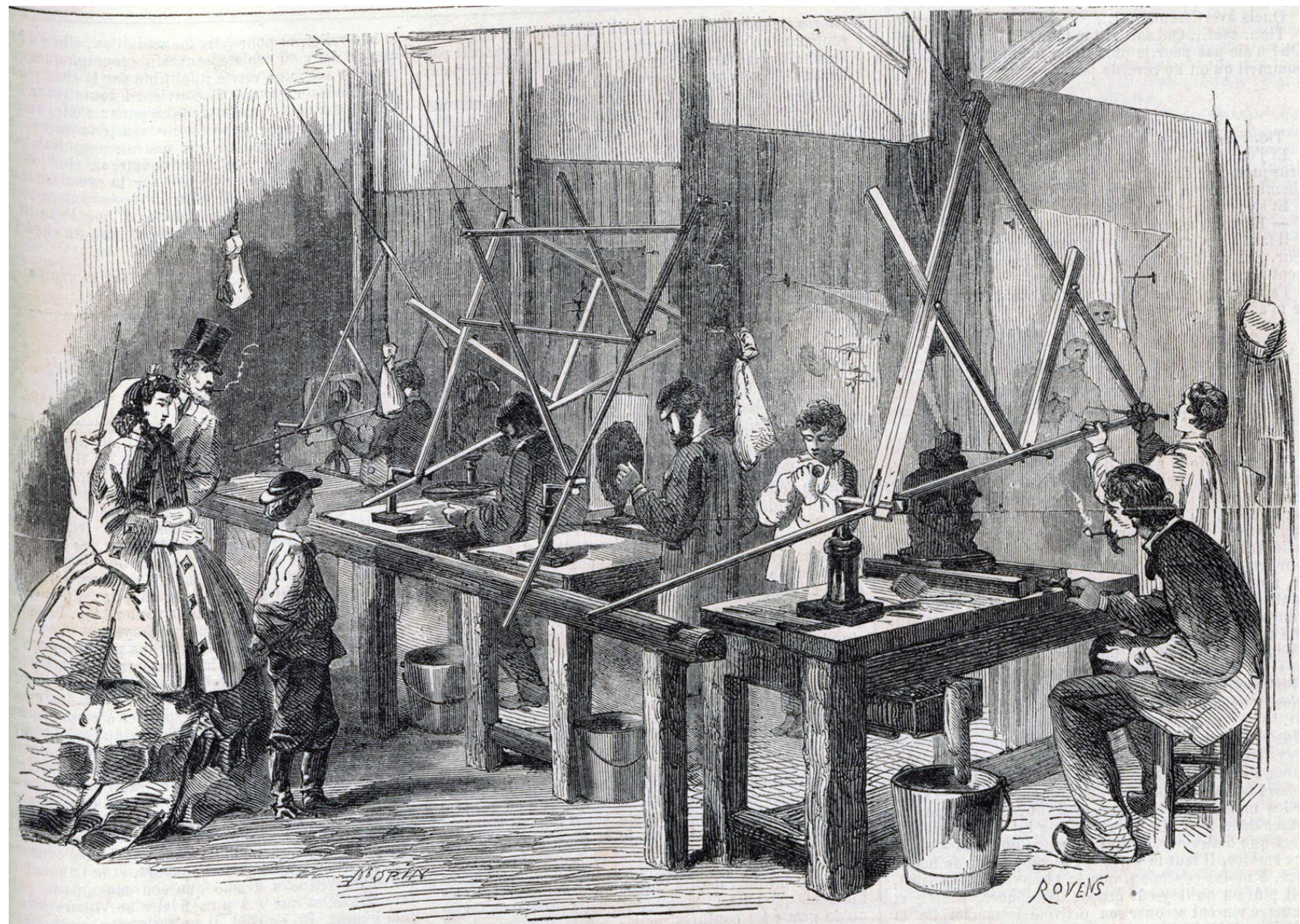

19th century studio of statues copying using a 3D-pantograph (ink drawing, artists E. Morin, E. Rovens, 1864) $)^{11}$

A minimum size of the model clay block depends on the size of the stone block under fabrication and, ultimately, is determined by the error of the pantograph mechanism. The size of the model block is also determined by how convenient it is for one or two workers to handle (sculpt, correct, carry, install, shift, turn, etc.) such a block. The modern 3D-pantographs used by sculptors $^{10}$ (see Fig. 1) allow enlargement of the object model by up to 6 times. Thus, by a clay block model size, say, $50 \times 50 \times 50 \mathrm{~cm}^{3}$, which can be made hollow to reduce its weight and shrinkage, the stone blocks up to $3 \times 3 \times 3 \mathrm{~m}^{3}$ can be processed on a not very large pantograph.

It should be noted that by installing a stone billet on the pantograph, a clay model of the block suitable for this billet can be quickly selected. This feature is extremely useful exactly in the case of the polygonal type of masonry, since in such masonry, blocks often have a complicated shape that requires a lot of preliminary measurements while selecting a billet.

After the mentioned copying process with the specified scale, the wall of stone blocks is assembled without any adjustments using rollers, levers, blocks, winches, and primitive cranes of the time. The front side of a stone block can be copied from the front side of a clay model, but it can be dressed or refined after the polygonal structure assembly.

When a polygonal masonry is built on a leveled reinforced ground, the first course is formed of not large stone blocks having a flat base, which are processed by the corresponding clay models. The stone blocks of the second course are usually larger than the blocks of the first course (see Photos. 1-4, for example). Why is that? Why are the large stones of the second course not put on the equally large or even larger stones? Everything is simple. Only by adding the soil under the not large blocks of the first course and putting small stones as wedges under them, it is possible to take up the side gaps between the large stone blocks of the second course, i. e., 
R. V. Lapshin

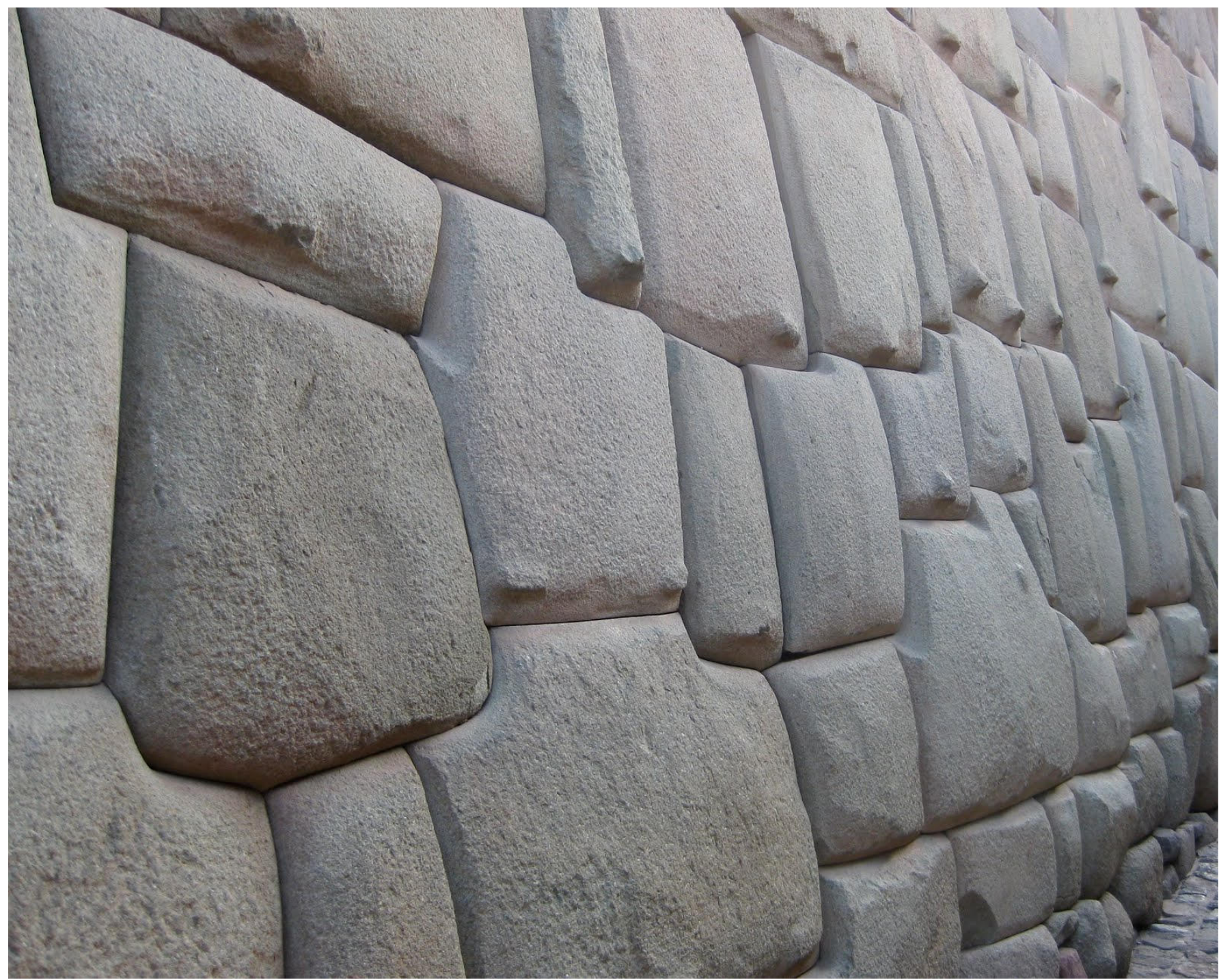

Photo. 1. Cusco (A. Kuusivaara, 2017)

correctly locate these blocks relative to each other. Only provided that the relative position of the blocks of the second course is correct, the rest courses can be laid with minimal gaps.

This peculiarity is one more confirmation that the wall of polygonal blocks of the type under consideration was not built course after course with fitting the stones in-site, ${ }^{3}$ but was fabricated by a reduced clay model and then it was only assembled. During the course-after-course construction, the first course of the masonry would always consist of the largest stone blocks, since according to this approach, both the mounting surface for the next stone block and this stone block itself are successively made in-site.

If the base of the not large stone blocks of the first course stands out of the general aesthetics of a particular polygonal masonry, then it can be hidden by a layer of soil (see Photo. 10). The soil being added will be compressed and the inserted small stones-wedges can crack and crumble under the masonry weight, then the masonry will slide apart. To prevent such event, solid wedging stones having no visible defects should be used and not in one but in several places; the soil under the building should be well compressed; after laying the first two courses, the work on this site should be stopped and the masonry should be observed for some time, etc.

When a polygonal masonry is located on a bedrock, the bedrock is pre-prepared. For example, $\mathrm{L}$-shaped recesses are fabricated in the bedrock. Then, not large blocks of the first course are formed from clay on the prepared section of the rock, which are made hollow to reduce their weight and shrinkage. After drying, the blocks are removed from the bedrock and put in the pan- 
Fabrication methods of the polygonal masonry in megalithic structures of Peru

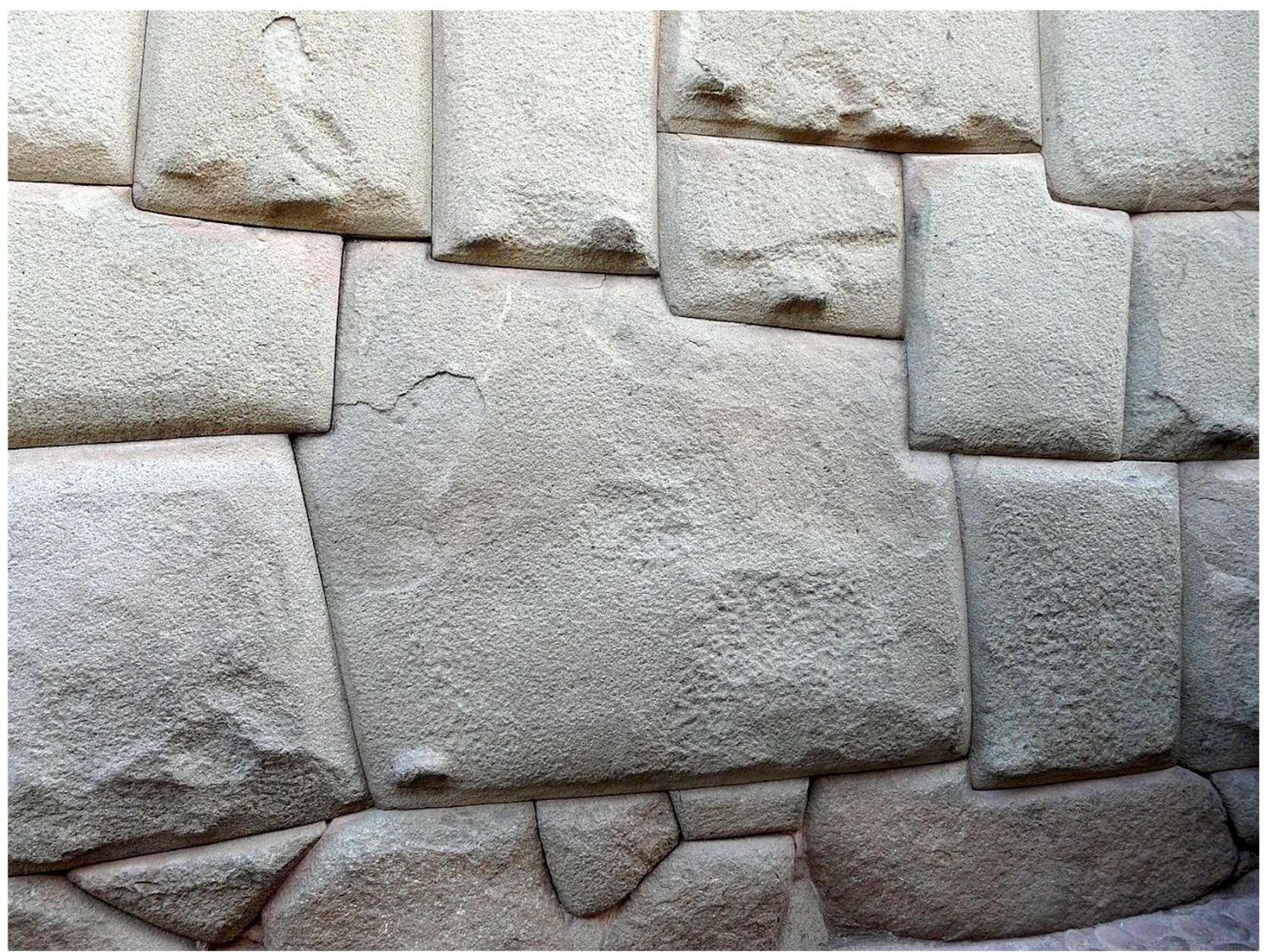

Photo. 2. Cusco (Gvillemin, 2008)

tograph in place of a stone billet (Table B in Fig. 1). Using the pantograph, reduced clay models are fabricated by the clay blocks of the first course. The obtained models are dried.

To avoid damage to the lower surface of the model blocks of the first course, the model blocks are put in beds with a flat base by pressing them into raw clay bars. The correct mutual position of the model blocks of the first course is determined by abutment of these blocks to each other along the side faces. To reduce the error of the relative position, one should aim to make the areas of the side faces of the first course blocks comparable to the areas of the bases of these blocks. The correct mutual position of the first course blocks at the construction site of the model wall is reached by adding soil and putting small wedging stones under the beds of these blocks.

The proposed method of geometry transfer from a small clay model to a large stone block using a 3D-pantograph does not require the detailed drawing of the block geometry. The builder should actually sculpt approximately the desired interface between the model blocks in accordance to the general idea of the sketch with his own hands (applying spatulas, straighteners, scrapers, etc. tools), then lay this block in the model wall, where this block would be finally fitted to the neighboring model blocks under its own weight and with small corrections of the builder. No precise dimensions need to be held here.

\subsection{Usage of replicas}

Not very complicated interfaces between large blocks are fabricated using replicas. A "pancake" of a constant thickness is pressed/rolled out of the clay. The raw pancake is put on a stone block which surface replica should be made. After solidification, the replica-pancake is taken off. By periodically applying the obtained low weight replica-pancake to a heavy mating stone block, the excess material is gradually removed in the needed areas until full fitting of the replica to the block.

If a higher accuracy of the relief transfer is required than the replica-pancake is capable to provide, then a replica of the replica is produced. First, by applying a raw clay bar to the selected 
R. V. Lapshin

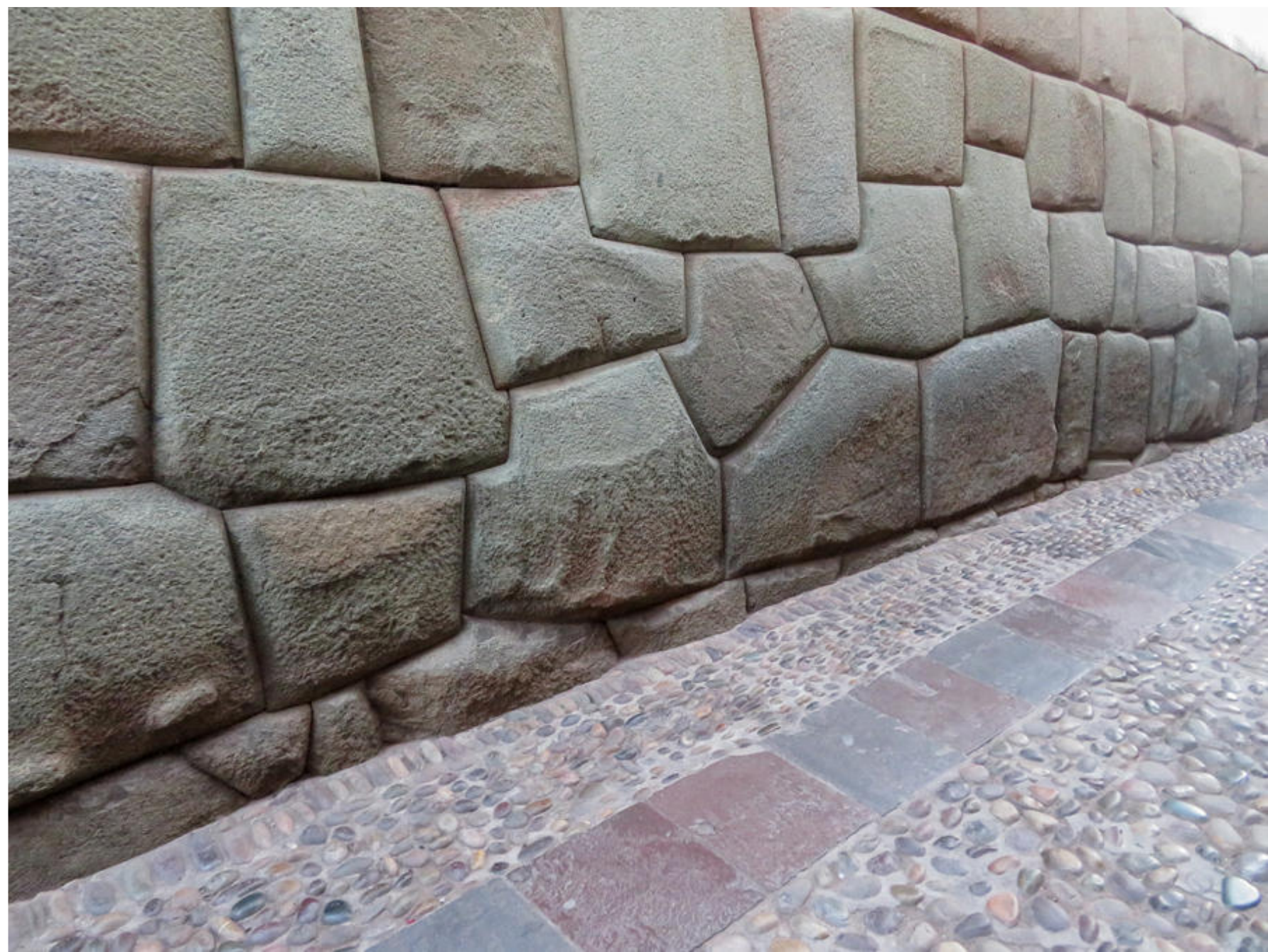

Photo. 3. Cusco (S. N. Kozintsev)

area of the stone block, an imprint of its surface is made. After solidification, another imprint is made in raw clay by the obtained replica. After drying, the replica of the replica is further used as a copy of the surface area of the stone block when making the mating part of the stone masonry.

In another method, a clay rim is installed along the perimeter of the selected area of the stone block, after that the resulting container is filled with gypsum. After solidification, the obtained replica is imprinted in a raw clay or, having installed a rim, one fill the resulting container with gypsum (the surface of the gypsum mold is precovered with a substance preventing bonding of the poured gypsum to the gypsum mold). After drying, the resulting replica of the replica is further used as a copy of the surface area of the stone block when making the mating part of the stone masonry.

The replicas were also used in the sites where the stone structures of large blocks were abutted upon rocks. The replica was taken from a pre-prepared rock section and then applied to the processing stone block or, vice versa, the replica was taken from a processed stone block and then applied to the processing rock. It all depended on what was more convenient in each particular case. Since very large stone blocks are like rocks - they being extremely difficult to move, the replicas were also used for joining large blocks to very large blocks and very large blocks to other very large blocks.

The larger are the sizes of a stone block, the larger and heavier are the replicas fabricated by it. Therefore, beginning from a certain size of the stone block, replicas have to be taken from sections of the stone block. To ensure the correct mutual position of the replicas on the processed mating surface of the block/rock, the sections of the neighboring replicas should be partially overlapped. The disadvantage of the replicas is a higher interface error of the surfaces of the 
Fabrication methods of the polygonal masonry in megalithic structures of Peru

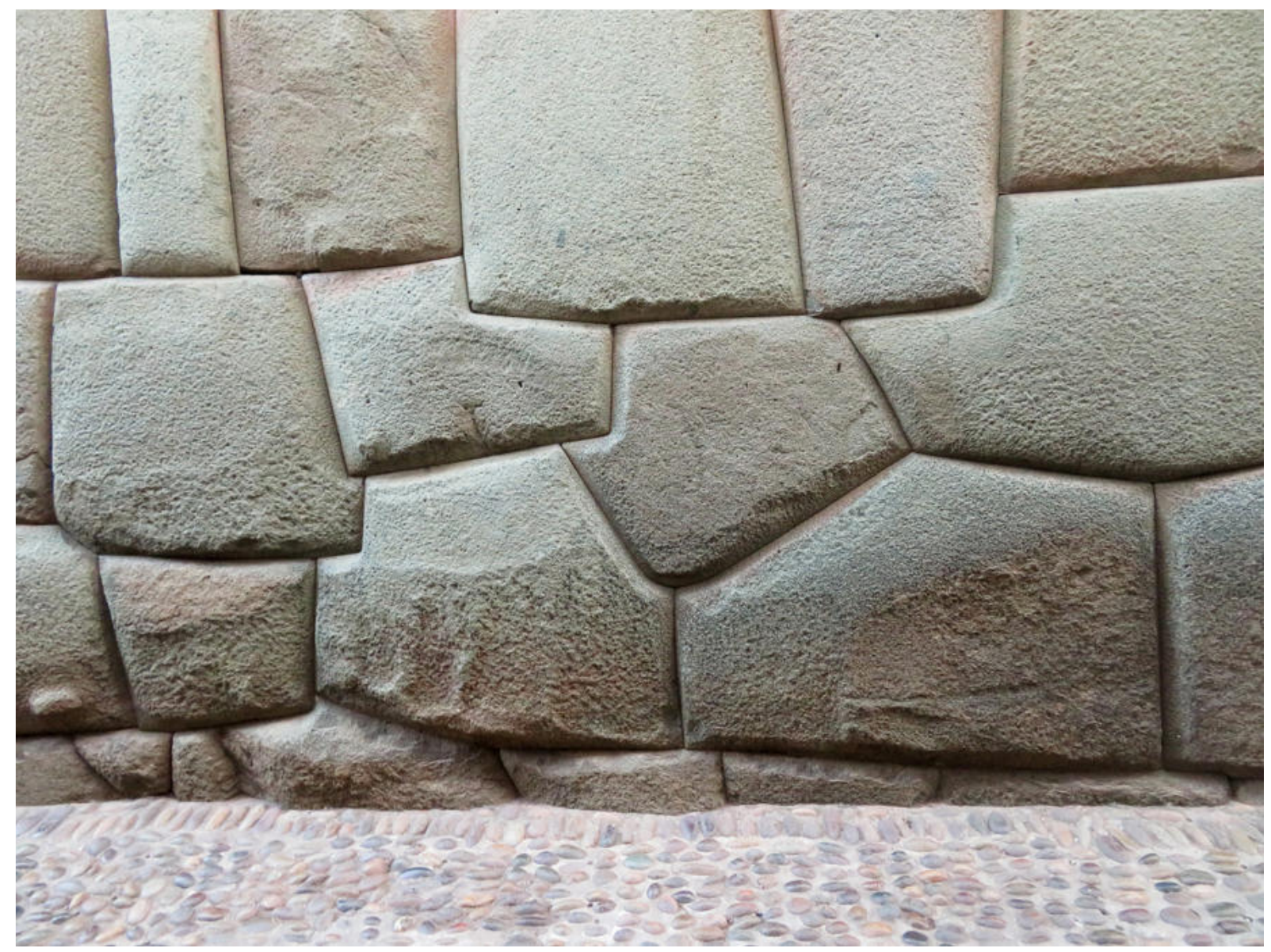

Photo. 4. Cusco (S. N. Kozintsev)

adjacent blocks in comparison with the pantograph and a higher fabrication laboriousness in comparison with the reduced model of the block.

The advantage of the replica is that just one of the mating surfaces of the adjacent blocks is processed upon a model (replica); the original surface is processed arbitrarily (independently). In contrast to the replica, it is necessary to process both mating surfaces according to the model in the pantograph method. There are no arbitrarily processed surfaces in the pantograph method.

\subsection{The main problem}

What does a stonemason has to continuously do while fabricating blocks fitted to each other through a complicated profile? The stonemason has to repeatedly apply one stone to another in order to determine the areas where the excess material should be removed. When the stones are small, it is easy to do. But how to do this when the weight of the stones is hundreds of kilograms or several tons? The suggested methods just allow us to solve this problem. It is no longer necessary to repeatedly move a heavy matching block.

\subsection{What else a clay model of the object is needed for?}

It is always extremely useful to have a small model of an object consisting of many parts of a complicated shape connected to each other in a complicated way; to turn each block in hands; to evaluate proportions more precisely; to correct the blocks if something is not likable in their shape or fitting; to assemble/disassemble the model wall to check for the fundamental possibility of assembling an object containing key elements; to assemble/disassemble the model wall to analyze the operations for moving, mounting, and installing heavy stone blocks; to see in advance how the object will look after construction completion. After all, in those days, architects and builders had no computers to rotate a component in three-dimensional space on a monitor screen or, creating a virtual reality, wander around the future construction long time before its 
R. V. Lapshin

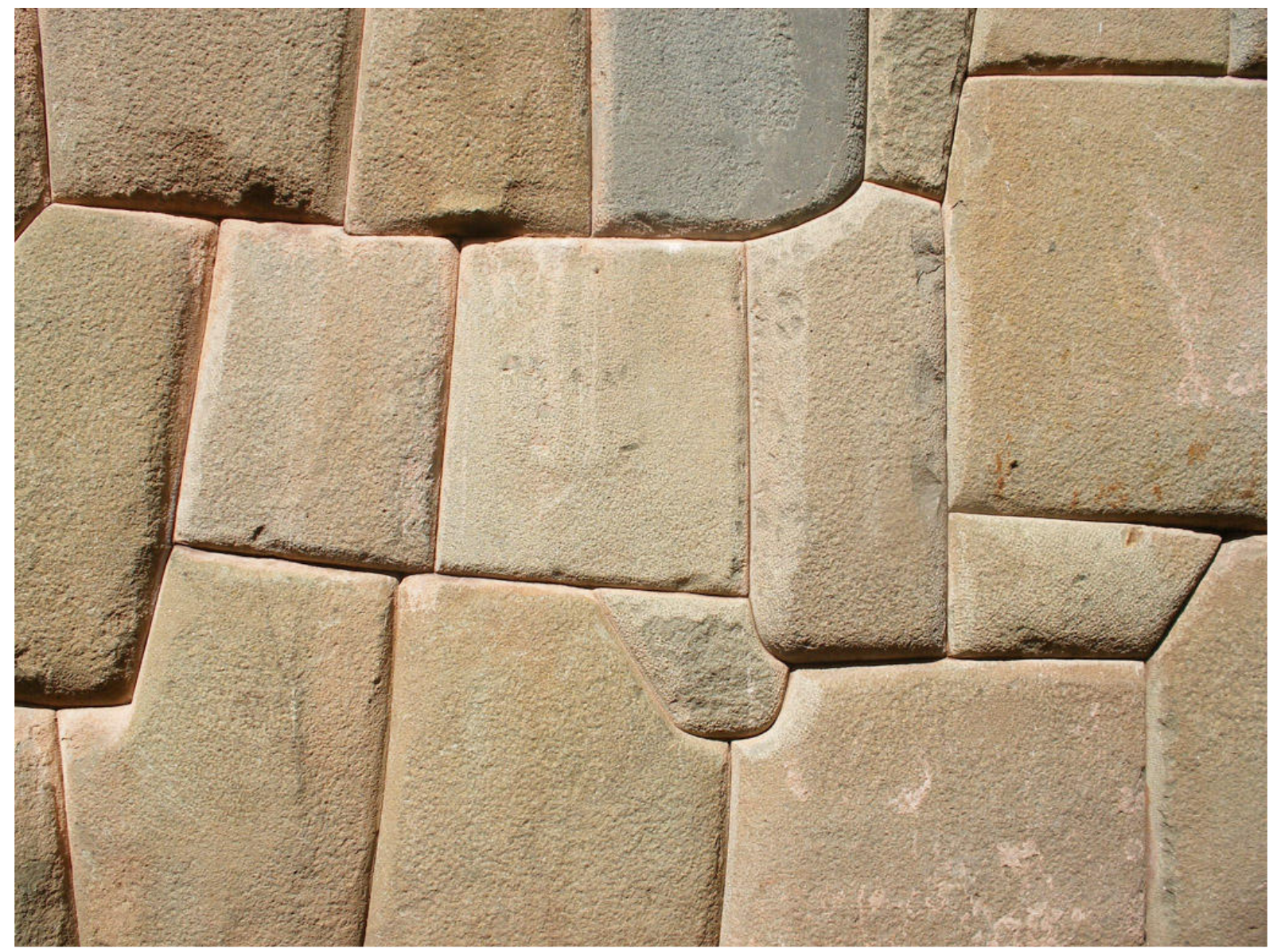

Photo. 5. Cusco (R. Mortari, 2013)

erection. Even in our time, the making of scale models in architecture and planning has not lost its relevance.

It is well-known that the region, where the polygonal masonry was used, is earthquake-prone. ${ }^{12}$ Therefore, by creating a model of the building with lock blocks and shaking it, one could see how the object would behave in an earthquake, and then, if necessary, make appropriate corrections to the project. Other methods did not simply exist in those times, the calculations were rough, and intuition and experience could fail.

On the upper faces of a number of stone blocks, characteristic recesses for the bases of the blocks installed over draw attention. ${ }^{2,3}$ Some of these recesses spread over two or even three adjacent blocks thereby providing bonding of the blocks. The recesses ensure in accordance with the principles of stable equilibrium that the blocks would return to their initial position in the event of a small horizontal displacement caused by an earthquake. The recesses under consideration in the upper faces of the blocks and the corresponding protruding parts at the lower faces of the blocks installing over are fabricated while sculpturing the clay model.

Since the clay model of the wall is building bottom-up and drying course after course, then, in theory, the shallow depressions should occur naturally in the bases of the model blocks, which, being softer (wet), weight down on the harder (dry) blocks located under them. The materials available to date do not allow us to confirm or disprove the presence of such depressions with certainty.

\subsection{What are the advantages of a pantograph over a replica?}

When we apply a replica to a processing extensive surface with a complicated topography, we do not clearly see where and how much material should be removed. Therefore, when working with a replica, we need to mark it with something, say, chalk or charcoal, and, while applying it to the processing surface area, slightly rub it to mark the locations where the material should be removed. Remember, what the dentist does after filling the tooth. He puts a piece of carbon pa- 


\section{Fabrication methods of the polygonal masonry in megalithic structures of Peru}

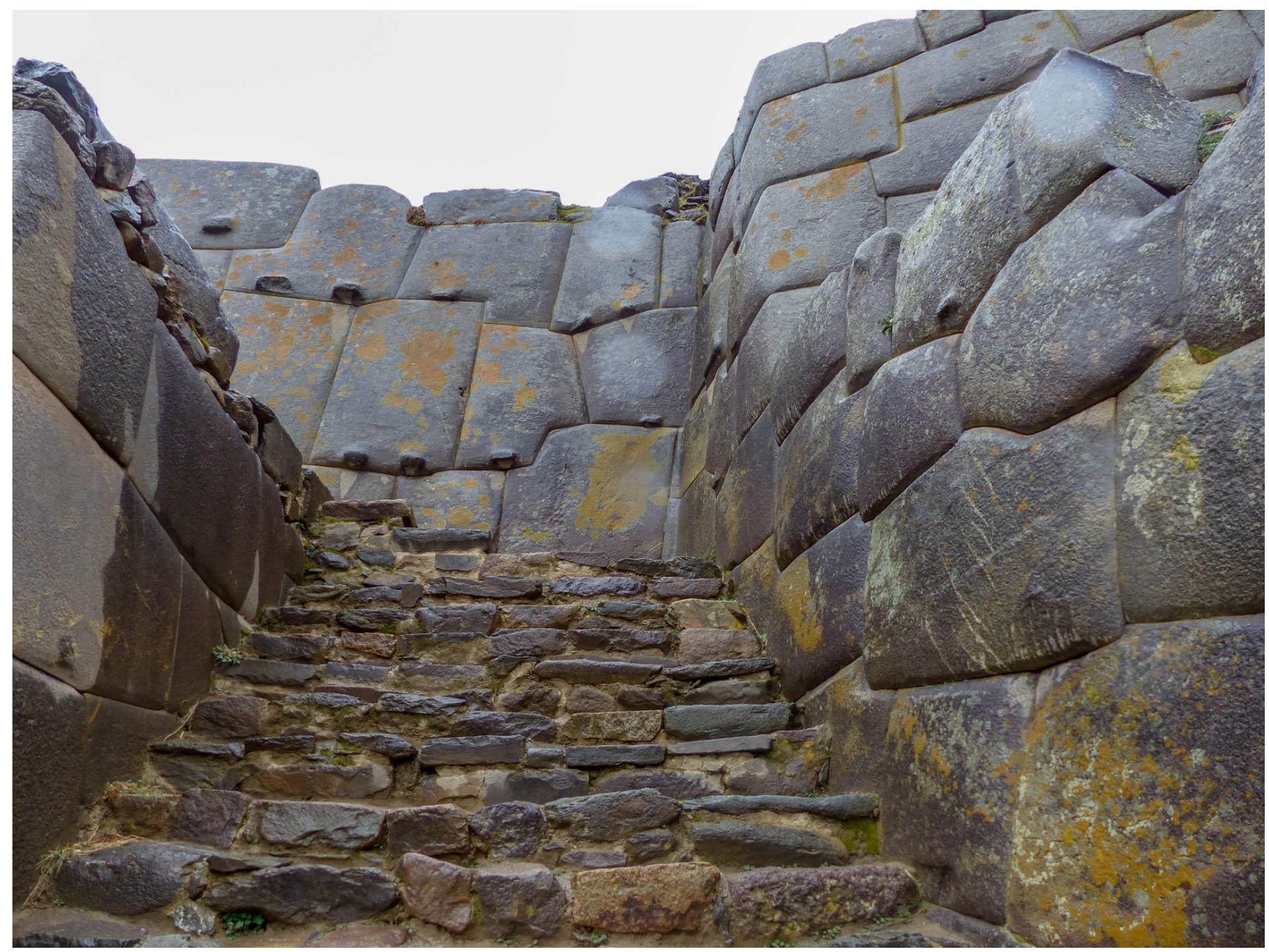

Photo. 6. Ollantaytambo (C. Jansen, M. Düerkop, 2016)

per on the filling and asks to close your mouth and slightly rub it with teeth. After that, the dentist removes a little bit of the filling material in the marked place. Then he repeats the process several times, until the teeth when closing take the usual position.

Working with a pantograph, a sharp probe (Pointer $\mathrm{A}$ ) is applied to the clay model, and a pointer (Pointer B) mechanically connected to the probe by means of a parallelogram mechanism is applied to the processing surface of the billet. In contrast to the replica, due to the small area of the probe and the pointer, the topography measurement is actually carried out at a surface point, and it is clearly visible at what exact point; the entire surface is completely open.

Moreover, the pantograph allows one to clearly determine the thickness of the material to be removed at any point to which the pointer is directed. Therefore, the excess material can be removed for significantly fewer attempts. All these result in increasing productivity abruptly. The highest productivity is achieved when two people work on a pantograph. One person with a pantograph pointer shows a location (point) on the stone billet and reports the thickness of material that should be removed at this point, and the other person with a hammer and a chisel removes the specified amount of the material.

Another advantage of the pantograph in comparison with the replica is that it is much faster and easier to touch the clay model of the block with the almost weightless probe (the device is balanced by a counterweight) than to apply a relatively heavy replica to a stone billet, and then in addition to slightly rub with this replica by the billet.

Also, the pantograph allows to easily keep proportions set by the architect, that, in case of the replicas, have to be done by eye by spending a long time by selecting billets of suitable size. Imagine that you need to accurately fit a structure into some unchangeable or difficult-to-change 


\section{R. V. Lapshin}

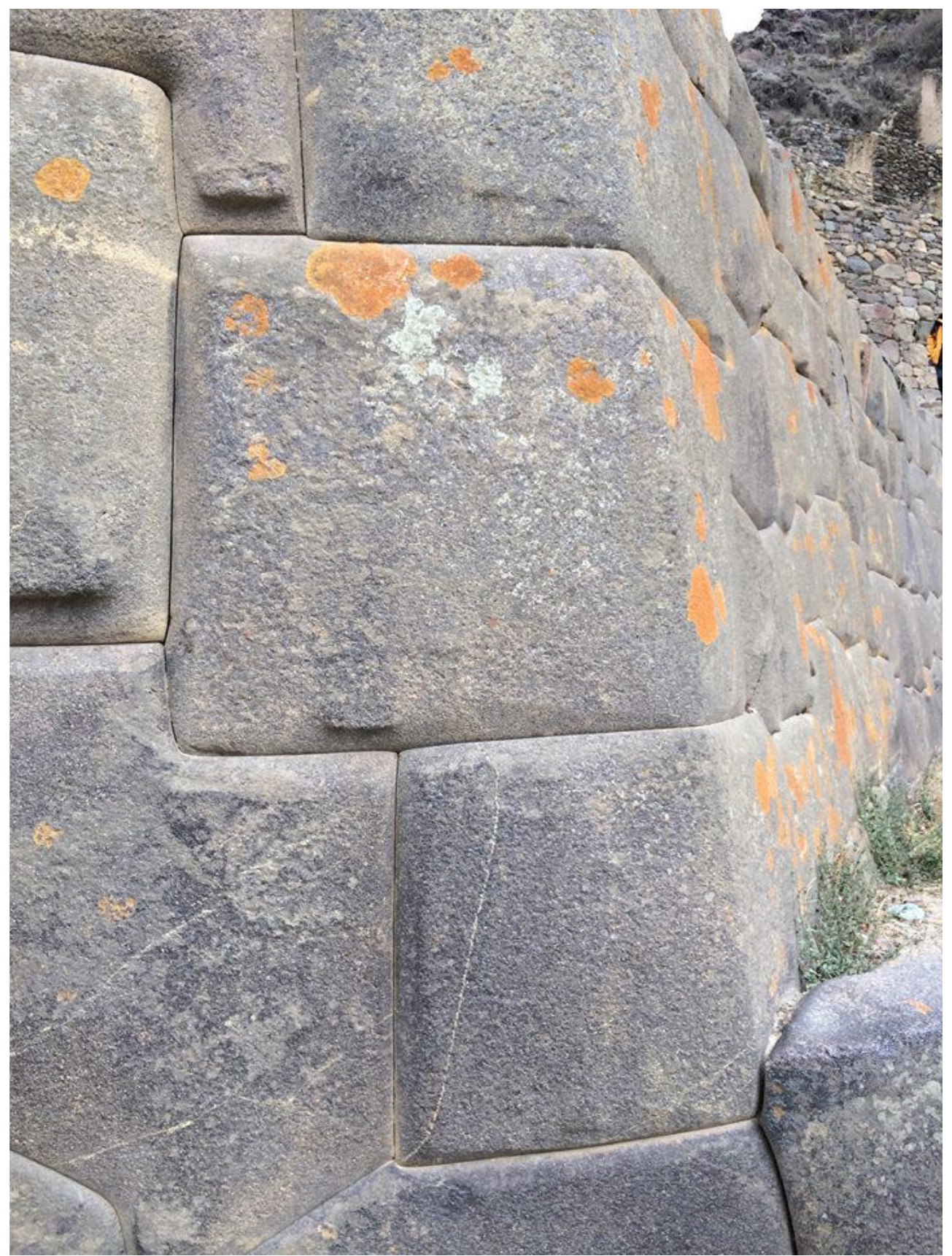

Photo. 7. Ollantaytambo (B. Everett)

dimensions, say, between two rocky outcrops or into a cave. To do this, it is enough to measure the distance between the rocky outcrops, the size of the model, divide first by second and set the obtained enlargement factor in the pantograph.

What else does the use of the clay model blocks and the pantograph give? Let the outer side of the wall is needed to be made with a slope. To do this, it is sufficient to lay a raw clay model of the wall on the back side, to install the stops that set the required slope, to put a flat surface on top of the front side, to allocate suitable weights above. Instead of the weights, tightening clamps can be used. After some time, the clay model of the wall will be deformed properly. In this method, the specified angle can be kept very accurately along the whole length of the wall.

\subsection{Reverse approach: clay model creation by a stone billet, fabrication of an interface surface and its transfer to the stone billet}

According to the method described above, first, a model was created by a sketch, and then a stone billet was selected for each block of the model. This approach allows us to repeat many times a section of the wall (if necessary, at different scales) using the same clay model each 


\section{Fabrication methods of the polygonal masonry in megalithic structures of Peru}

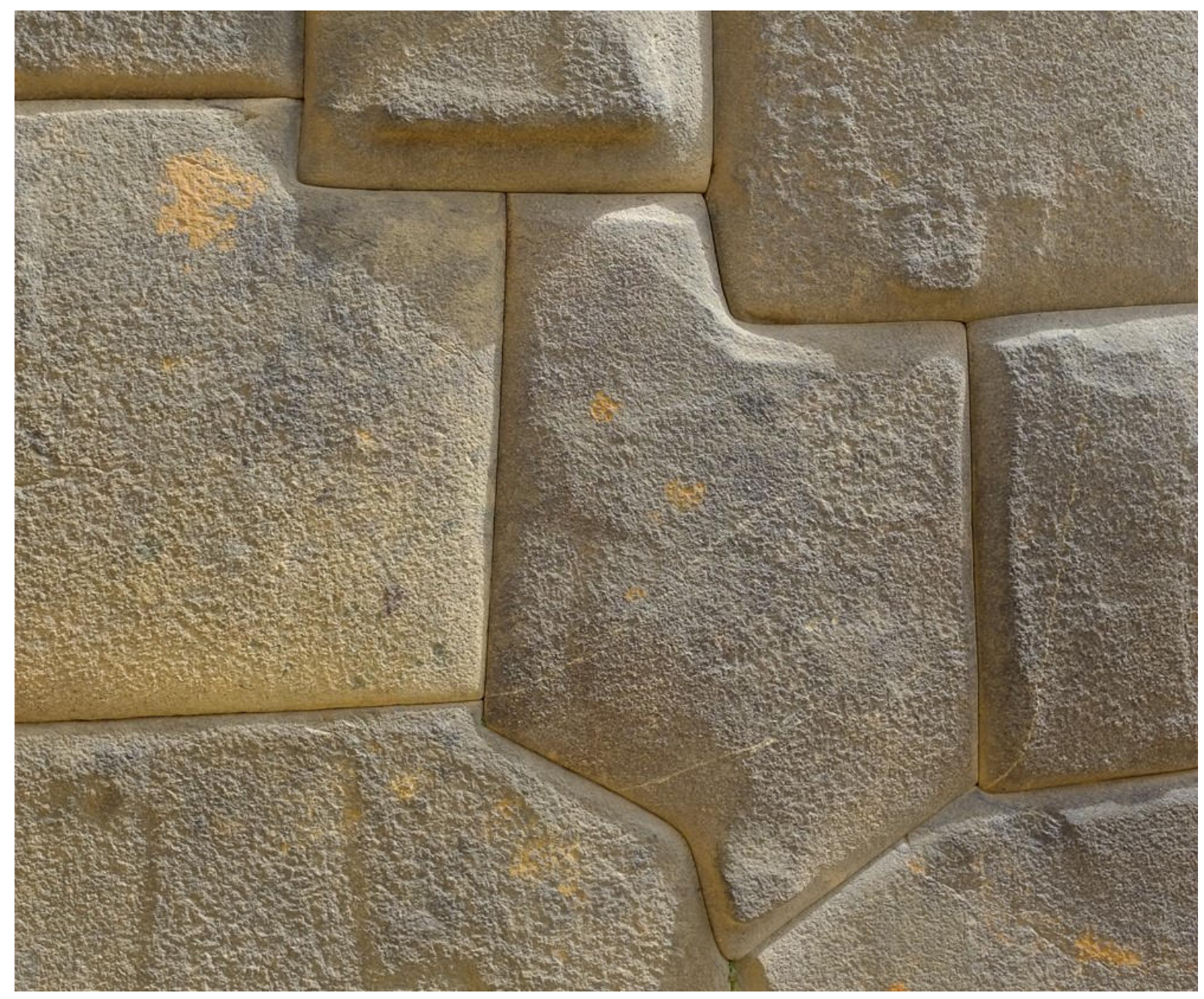

Photo. 8. Ollantaytambo (C. Boudou, 2013)

time. The drawback of the method is the large volume of the chipped off material of the stone billet. The analysis shows that a reverse method was mainly used for the polygonal masonry.

In the reverse method, first, a reduced clay model is created by a stone billet of arbitrary shape using the pantograph. To do this, a piece of raw clay is impaled on a pointed, say, three/foursided metal pin located in the center of the rotating platform intended for a model (Table $A$ in Fig. 1). Due to this pin, the model can be removed from the pantograph at any time and precisely returned to its original position. Clay is added to those places of the model where it is not enough. Removal of clay excess is carried out directly with the metal pointer (Pointer A in Fig. 1; instead of a tip, a suitable tool can be attached to the pointer, for example, a wire loop, cutter, scraper, etc.) of the pantograph, which probe (Pointer B) moves along the surface of the stone block vertically up, then a small turn of the platform with the billet (Table B) around the vertical axis, then down, again a small turn, again up, etc. ${ }^{10}$ Owing to the pantograph, creation of the clay model body does not take much time.

At the next stage, a prototype of the wall is assembled from the obtained clay model blocks. The blocks still have no specially prepared mounting surfaces. Taking into account the size and the shape of the blocks, each block location is defined in the wall prototype. An architect-builder approximately layouts the contours of the future interfaces on the clay model of the wall, which should reflect: a conceived style, ensure stability of the created polygonal masonry, and minimize the labor of processing of the mounting surfaces. Further on, according to the accepted layout, the clay is cut out in the model block regions by which the blocks will adjoin each other.

Next, the wall model is being assembled from the obtained model blocks. By small corrections, the blocks are matched more precisely to each other. If the block model was occasionally damaged during the manipulations, the shape of the model in any location can always be restored 


\section{R. V. Lapshin}

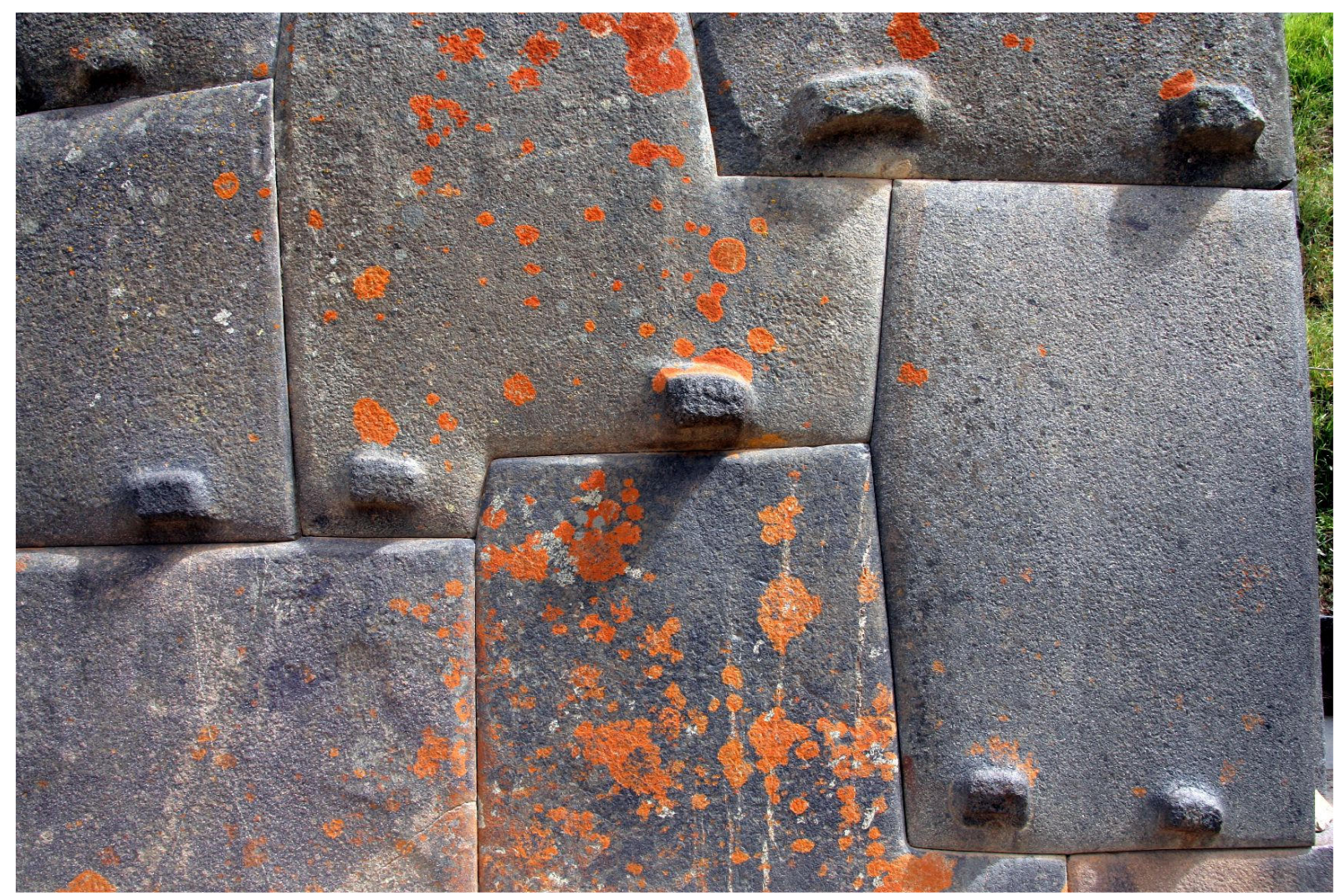

Photo. 9. Ollantaytambo (B. Foerster, 2009)

by placing the block model back on the pantograph (on the above indicated pin) and by comparing with the shape of the original stone billet. Then the wall is being dried. First, the bottom course is dried, then the next one, and so on. During the drying shrinkage process, the model blocks are matched more closely under their own weight.

At the final stage, the model wall is being disassembled. The clay model of the block is put back on the pantograph (on the above indicated pin) and the mounting sites are transferred on the stone billet corresponding to this model block using a hammer and a chisel.

In the described method, the stone block is installed in the pantograph at least twice. To accurately return the stone block to its initial position, two lines radially diverging from the center of the platform (Table B) can be plotted on the platform. At the first installation of the stone block, alignment marks are applied to the surface of the stone with a paint in the places where the lines come out from under the block.

\subsection{Several more advantages of the pantograph}

The use of a reduced clay model and a pantograph allows to fabricate blocks directly in the quarry where the stones are extracted. ${ }^{2,3}$ As a result, the finished stone blocks are carried from the quarry to the construction site. This approach significantly reduces the weight of the transported blocks and decreases the volume of the whole cargo traffic. Moreover, such organization excludes a large amount of construction debris on the construction site, which needs to be also transported somewhere after all.

Both the pantograph method and the replica method use auxiliary elements. In the pantograph method, these are the clay model blocks; in the replica method, these are the replicas themselves. To mate stone blocks in the replica method, the side surface of the block must be divided into several overlapping sections, each of which requires its own replica. If you mentally attach to the side surface of a non-edge stone block all the replicas made for it and by it, you will get a kind of a wheel, i. e., a fairly massive formation. If a replica of replica is used, then there will be two such "wheels" already. Thus, it is necessary to fabricate one "wheel" of replicas for each non-edge block in the replica of replica method. Let us compare such a "wheel" of rep- 
Fabrication methods of the polygonal masonry in megalithic structures of Peru

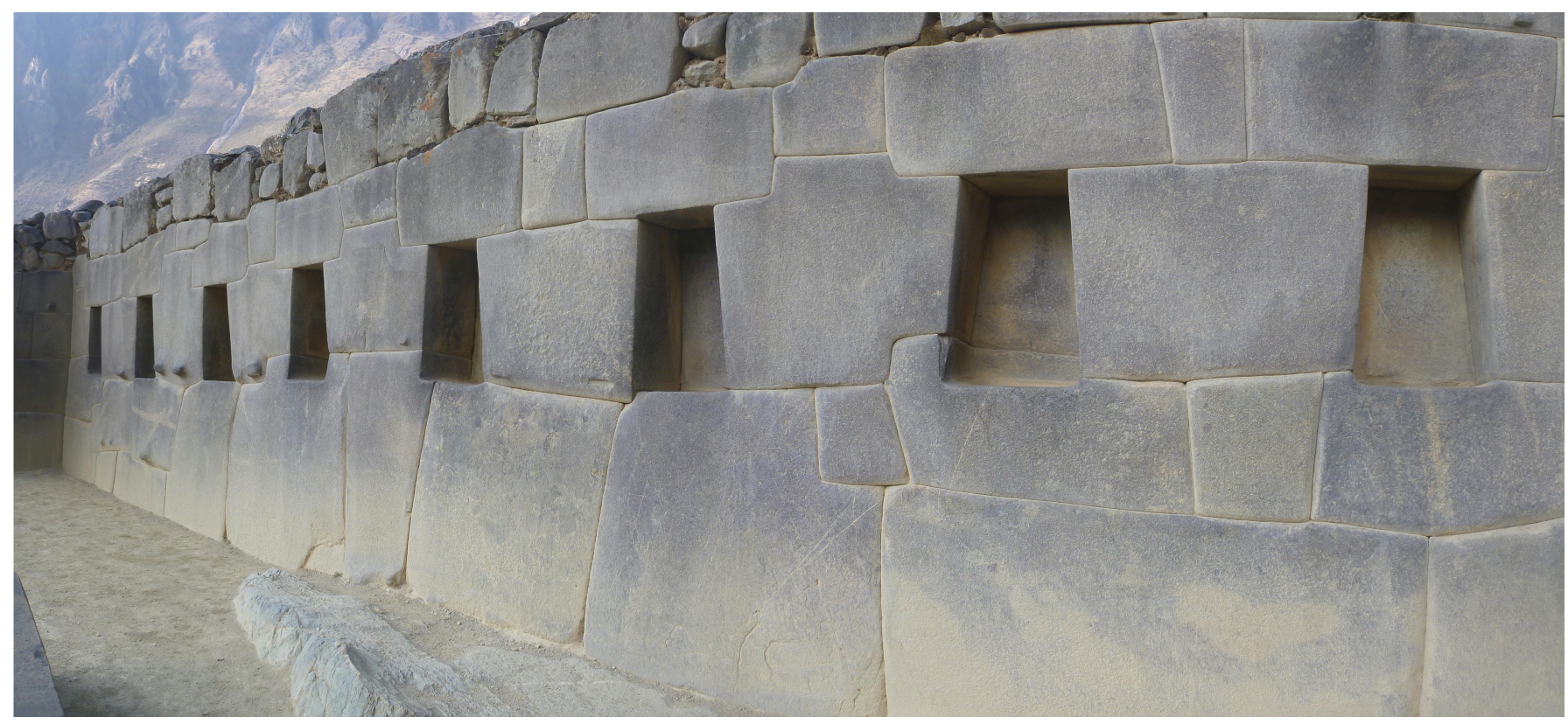

Photo. 10. Ollantaytambo (P. Adams, 2012)

licas with small model blocks in the pantograph-based method. The advantages of the pantograph are obvious.

\subsection{A method combining elements of the replica, clay model, and 3D-pantograph methods}

In the beginning, every second stone block of the first course is installed on the site of the future structure. The empty positions between these blocks will be occupied by blocks, which will be fitted to these initially installed blocks at the next stage using a clay model and pantograph. The base surfaces of the initially installed stone blocks are pre-treated properly to ensure their stability.

Besides the prepared base, the initially installed blocks have finally processed side faces also. The processing of the side faces is the straightening of the complicated initial shape of the stone billet by surfaces close to the planes with a hammer and a chisel. The faces of the initially installed blocks to the right and to the left of the base should, if possible, have a positive slope to the base to facilitate the subsequent installation of the adjacent blocks between them. The similar rule is applied later for every second block of the subsequent courses of the polygonal masonry.

Next, the space between the initially installed blocks is filled with clay. Actually, clay models of the blocks are created at the scale 1:1 in the spaces between the initial blocks. The side surfaces of these models contacting at the left and at the right with the side surfaces of the initial blocks are, in fact, their replicas. To decrease weight of the clay models and reduce shrinkage deformations during drying, the models are made hollow.

After drying, the clay model of the block is removed from the structure and installed in the pantograph on the place of a model (Table A). The corresponding stone billet is installed on the place of a copy (Table B). The pantograph is adjusted to the scale 1:1 (at the given scale, the placement of the model and the copy in the pantograph is only determined by the operation convenience). If necessary, one can quickly check the matching of the selected stone billet to the model with the pantograph.

Next, the interface surfaces are transferred from the clay model to the stone billet using the pantograph, hammer and chisel, as described above. After transferring the interface surfaces, the rest (arbitrary) faces of this block are formed on the remaining side surface of the stone billet. The processing of these faces is the straightening of the complicated initial shape of the stone billet by surfaces close to the planes. Further, these faces will no longer be processed. 




Photo. 11. Ollantaytambo (A. Fuchs, 2008)

The stone block obtained this way is finally put in its place in the polygonal masonry. Having finished the first course, the next one is produced in the same way. For better vertical bonding of the blocks, every second block of the previous course should be approximately brought to the middle of the next course by height, if possible.

As in the above methods, the stone blocks of an arbitrary shape are used in the described method. Since the method has no full-fledged clay model of the structure, in order to put together the original stone blocks well and thereby minimize the amount of material to be chipped off during processing, it is desirable to preliminarily lay out the stone blocks on the ground with the back side down, one next to the other.

The method disadvantage is the high laboriousness associated with the fabrication of the clay model of the block on the scale 1:1. Nevertheless, in comparison with the replica replica method, this method is capable to provide a much higher accuracy of the interface between the contacting surfaces when it is necessary. As in the replica cases, about half of the side surface of the stone blocks is processed arbitrarily in this method.

\section{9. "Planetary" pantograph for use in construction}

Modern pantographs used by sculptors have two synchronously rotating platforms. A model is installed on one platform (see Table A in Fig. 1), and the enlarged copy of the model is installed on the other platform (Table B). Usually the enlarged copy is hollow, so the weight of the copy is low, as a rule. The platform of such a pantograph while using it in the construction will be able to withstand stone billets weighing up to about $700 \mathrm{~kg}$. When a sculpture is large and heavy, its model can be divided into several parts. An enlarged copy can be fabricated for each such part; then a large sculpture is assembled from the obtained enlarged copies. However, this is not our case.

The modern pantograph is not suitable for working with large and heavy billets. Instead of the existing design, one can offer the following "planetary" pantograph. The heavy billet in such a 
Fabrication methods of the polygonal masonry in megalithic structures of Peru

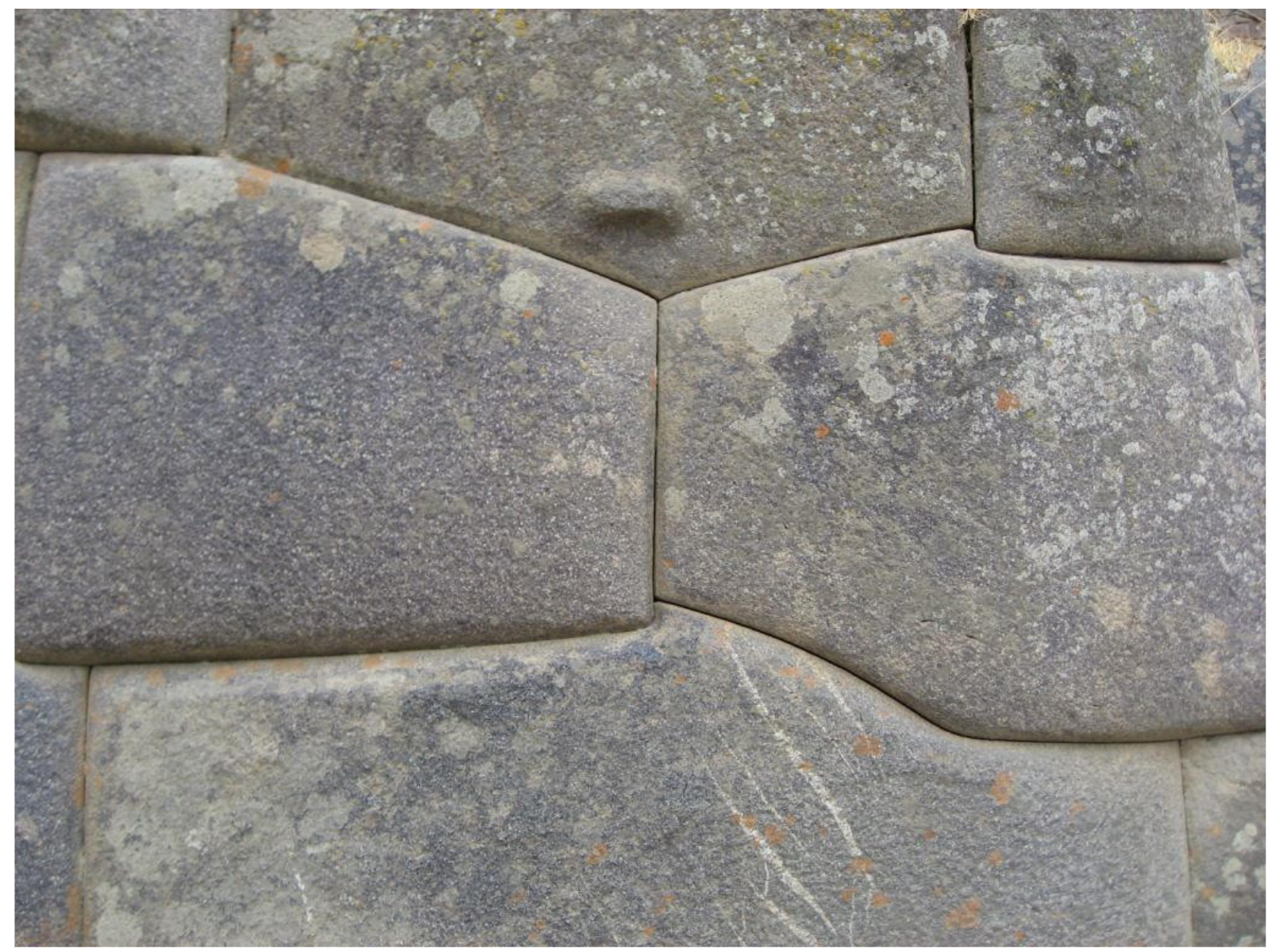

Photo. 12. Ollantaytambo (B. Everett)

pantograph is simply installed on a plane site and the frame, to which the pantograph boom and the platform with the model are attached, is turning during work in the horizontal plane around the stationary standing billet. As the frame turns, the model also turns around its vertical axis at the required angle (retains its original orientation in space) using an appropriate mechanism. One revolution of the support point (Pivot in Fig. 1) of the pantograph boom around the billet corresponds to one revolution of the model around its axis.

In contrast to the existing pantograph, the planetary pantograph occupies more space, and the person using the pantograph has to move while working along with the turning frame around the billet. These features can be attributed to the shortcomings of the planetary pantograph, which, however, are not critical in the construction field at all.

\subsection{The bulge of the block front side, the swell in the lower part, the cusps at the triple junctions}

The typical bulge of the front surface of the blocks as well as the presence of a swell in the lower part of the blocks (should not be confused with the bosses) found in some structures often serve as one of the proofs of the "concrete" and "plastic" versions of fabrication of the polygonal masonry. According to the "concrete" version, ${ }^{5}$ the blocks were cast from concrete; according to the "plastic" version, ${ }^{6}$ the stone mass softened by heating was used. In the "concrete" and the "plastic" versions, the partially solidified blocks were stacked one on another. As a result, the interblock gaps in the polygonal masonry were closed under own weights of these blocks.

In the proposed method, both signs - the bulge and the swell can appear by themselves at the stage of fabrication of the clay model of the wall unless the clay mixture was not thick enough and no sheathing was used on the front and the back sides. The bulge and the swell can also be produced intentionally while sculpturing the clay model.

Most likely, the bulge and the swell were given to the blocks intentionally. Both features increase the feeling of massiveness, grandiosity of the structure, its colossal weight; it seems to 

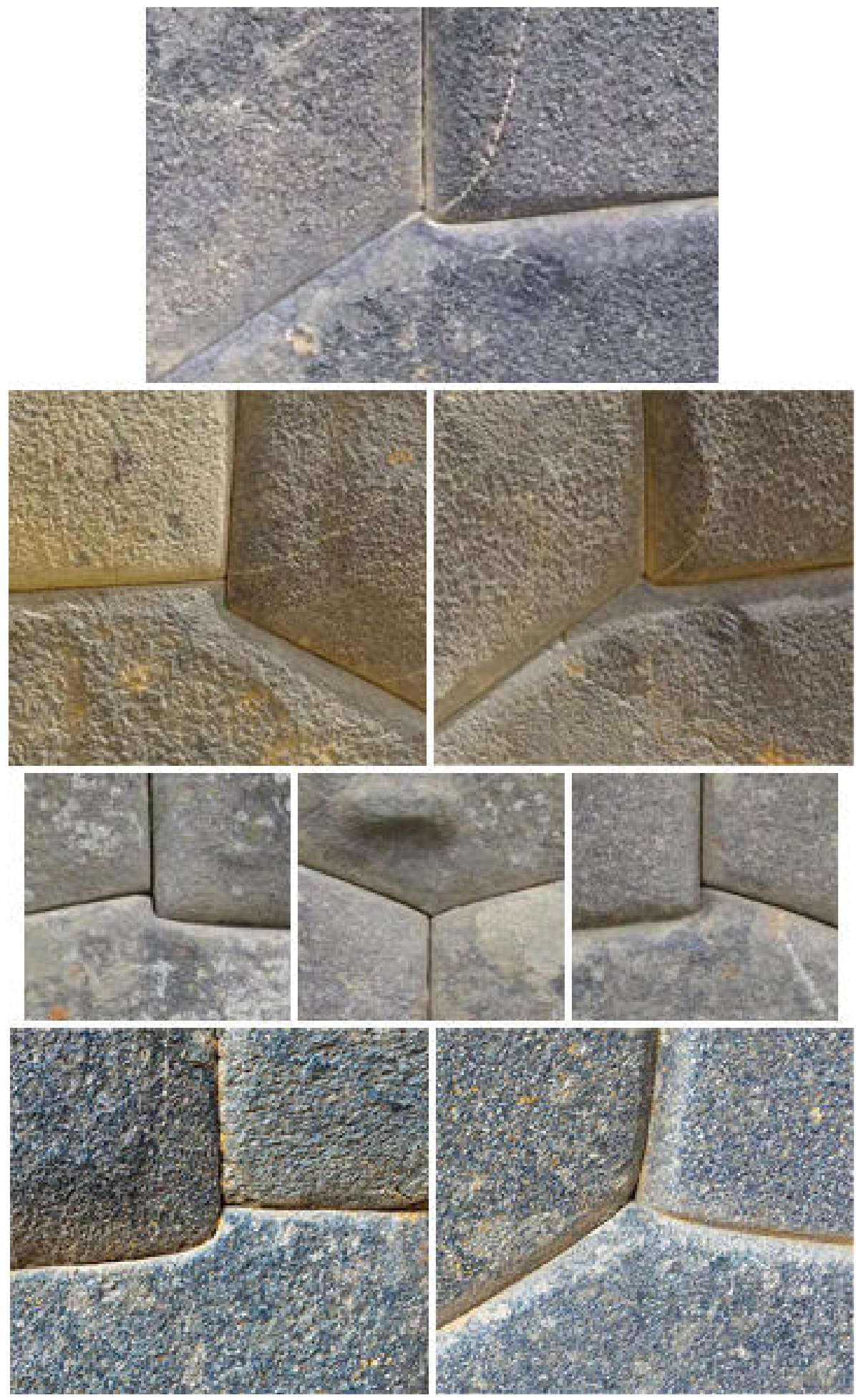

Fig. 2. Cusps and steps

us as if the stones are flattened under a huge weight. The bulge was also intended to demonstrate to the naive Indians the power of the arrived whites, who could "sculpt", if necessary, a building out of huge hard stones as if from dough.

Note that according to the proposed method, it is also possible to obtain large blocks from concrete, artificial granite and other materials by casting into a mold. Using the pantograph, the reduced clay model of the block is enlarged to the desired size. The enlarged clay copy is made hollow to reduce weight. Next, a mold is fabricated by the enlarged clay copy.

The cusps ("beaks") and steps (see Fig. 2) are clearly visible in the points where three adjacent blocks meet. These elements are produced while sculpturing the clay model and then transferred on the stone block with the pantograph. Besides a stop limiting movement of the adjacent 
Fabrication methods of the polygonal masonry in megalithic structures of Peru

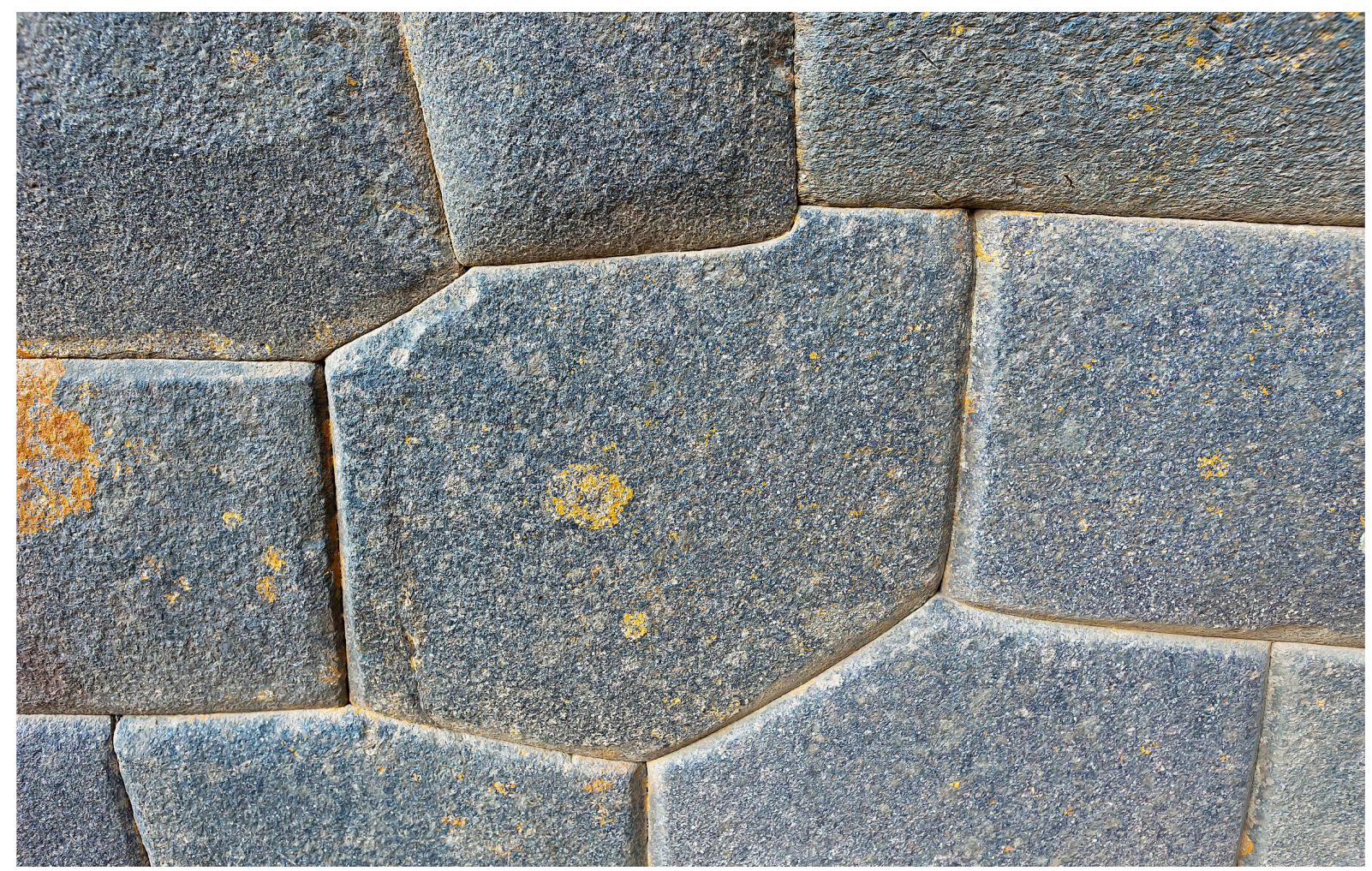

Photo. 13. Ollantaytambo (I. Otkalo, 2015)

block in the horizontal plane, the cusps give the polygonal masonry a special grace. According to the creators' idea, the cusps along with the parallelism of the smoothly changing curved edges were intended to give a sense of easiness of working with a stone. These features make the viewer think that the blocks are literally sculpted of a stone. And we must pay a tribute to the old masters; they succeeded in this technique!

Given the above, instead of the term "polygonal masonry", it would be quite fair to use the term "polygonal sculpture" in the cases when a stone structure is created on the basis of handsculpting of a clay model made in a certain artistic style with unique lock interfaces between blocks.

\subsection{Indirect dating by the observed destructions of the masonry elements}

The cusp is one of the weak points of the polygonal masonry in terms of strength. Thus, the cusps should fail first during the natural weathering process. Many stones in Peru are covered with lichen, so the biological factor must also be taken into account in addition to the weathering when estimating the rate of stone destruction. Surprisingly, the type of the polygonal masonry under consideration is perfectly preserved in the mountains (Cusco, Machu Picchu, Ollantaytambo, etc.), where the climate is characterized by sharp temperature changes $\left(15-20^{\circ} \mathrm{C}\right)$ during a day, by a lot of precipitation and by light frosts in winter (June-August). ${ }^{13}$

Besides weathering, a shift of stones in the masonry during a landslide move of the slope or during an earthquake ${ }^{12}$ can cause destruction of the cusps. It should be noted that the cusp cleavages could occur in the process of stone block fabrication, during transportation, installation, or restoration. Some of these cleft cusps can be partially repaired. The repaired cusps will look more sunk into the body of the masonry than the normal ones.

The study of the polygonal masonry from hard rocks (granite, andesite, basalt) shows that the cusp damages are present but they are few in number. The lack of noticeable destructions under fairly harsh climatic conditions and high seismic activity in Peru give a reason to assert the comparatively recent construction of the megalithic complexes. The estimated time of existence of the structures is about 300 years. 


\subsection{How to prove it? What should we look for and where?}

What can serve as a confirmation of the proposed methods of fabrication of the polygonal masonry? On the territory or near the complexes with polygonal masonry or in quarries, a construction debris should remain, in which fragments of clay model blocks and fragments of clay/gypsum replicas should be searched for. Certainly, first of all, we need to study the materials of the conducted excavations. It is not unlikely that some suitable fragments in shape, size, and materials have already been found and documented. Most likely, much of the debris was used for strengthening the ground under the next erecting structure. Therefore, in the case of setting up again any structure damaged by natural causes, the evidences in the form of the clay models and replicas should be sought in the ground under the structure itself.

Assuming that in the pantograph used by the builders, the clay model and the stone billet were positioned in the same way as in the modern pantograph, i. e., horizontally with the backside down (to fix the block in case of uneven back surface, wedging stones are used), then the chisel marks on the side surface of the stone blocks should go from right to left (chisel in the left hand, hammer in the right) and from top to bottom (at the beginning of the trace, the recess is larger than at the end). The marks themselves should be short parallel strokes arranged in vertical columns.

The chisel marks should be searched for on the stone blocks from hard rocks - granite, andesite, basalt. Soft rocks, such as limestone, have a high porosity; the surface layer of these stones is quickly destroyed by weathering. Moreover, the chisel marks on the limestone surface are easily destroyed during the subsequent smoothing operation by tapping. Because of weathering, there is also no sense to study the interface surfaces of the stone blocks from hard rocks that have lain in the open air outside masonry for an unknown number of years. To analyze an interface surface, one should take stones from some untouched masonry having minimal gaps, which could get a very small amount of moisture.

It should be noted that the several hundred years old masonry of stone blocks is most likely impossible to disassemble so as to keep the surface layer of stone intact at the contact points. The fact is that during the entire period of the masonry existence under the above climatic conditions, various physico-chemical processes took place at the contact points, which, depending on the process, resulted the contact point to be destroyed (with the sand formation) or, on the contrary, to be strengthened. An attempt to separate the sites, where the strengthening has occurred, will result in the destruction of the stone surface layer adjacent to the contact. Anyway, the sizes of the stones and their geometry will change after disassembling the old polygonal masonry. Therefore, it is impossible to assemble the blocks again so that there would be the former tiny gaps between them.

\subsection{Indirect dating by the time of the invention of the 3D-pantograph}

If we accept the proposed version of polygonal masonry fabrication with a pantograph, the structures of "incredibly" ancient Incas can be approximately dated by the years of invention/building of pantographs by Europeans. The pantograph for working with a flat drawing was invented in 1603-1605 by Christoph Scheiner. ${ }^{14}$ It should be noted that the information about the pantograph design was published by the author in the form of a separate book ${ }^{15}$ only 28 years after the invention.

Around 1710-1720, Russian mechanics Franz Singer and Andrey Nartov ${ }^{16}$ built a turning machine for copying medals. ${ }^{17,18}$ The machine was intended for production of medals in automatic mode by transferring a relief from a large size medal model. It is not quite correct to compare the Singer-Nartov machine with the modern 3D-pantograph used by sculptors (see Fig. 1), since the kinematic diagrams of these mechanisms differ greatly. Despite this, attention should be paid to the complexity of the machine mechanism, which notably exceeds the complexity of the modern pantograph mechanism. In particular, the probe movement along the model surface and the cutting tool application to the billet surface in the 3D-pantograph are carried out by the 


\section{Fabrication methods of the polygonal masonry in megalithic structures of Peru}

sculptor manually, whereas these functions are implemented in the given example of the machine without a human intervention. Note that in the 18th century, copying machines like this were built and used in many European countries.

In 1807, James Watt ${ }^{19}$ starts designing a mechanism ${ }^{20}$ intended for production of reduced copies of sculptures. ${ }^{21}$ The kinematic diagram of Watt's mechanism is close to the kinematic diagram of the modern 3D-pantograph. However, there are a number of differences. Instead of the ball joint, the boom is mounted on a universal joint; there is no a parallelogram mechanism; the model and its reduced copy are located horizontally, etc.

The kinematic diagram of the pantograph ${ }^{22}$ built by Benjamin Cheverton in 1826 is the closest to the kinematic diagram of the modern 3D-pantograph (see Fig. 1). Building the pantograph, Cheverton relied on the design previously proposed by John Hawkins. ${ }^{23}$ Just like the Watt pantograph, the Hawkins-Cheverton pantograph was intended to produce reduced copies of sculptures.

It should be noted that both the Watt pantograph and the Hawkins-Cheverton pantograph had a built-in engraver, whose milling cutter performed mechanical processing of the billet. An engraver is not required in the above considered methods creating the polygonal masonry. Therefore, the construction pantograph is mechanically simpler than the Watt and Hawkins-Cheverton pantographs.

There is no doubt that, having created a 2D-pantograph at the beginning of the 17th century, scientists of that time and, first of all, the inventor of the 2D-pantograph himself, Christoph Scheiner, immediately thought about creating a 3D-pantograph mechanism with which it would be possible to obtain reduced/enlarged copies of three-dimensional objects. Actually, for transition to work with three-dimensional objects, the 2D-pantograph just had to be fixed not in the cylindrical, but in a ball joint; the parallelogram mechanism should be allowed to rotate freely around the arm installed in the ball joint (pantograph boom), and the model and the billet should have the ability to synchronously rotate around their vertical axes by means of a chain (see Fig. 1) or a gear ${ }^{22}$ transmission.

Application of the chain transmission in the construction pantograph is more justified in comparison with the gear transmission. The point is that large dimensions and weight of the processing stone blocks result in large dimensions and weight of the used gear wheels. Moreover, the chain transmission makes it easy to change the distance between the rotating platforms, which is responsible for the pantograph reducing/enlarging factor. The distance change is carried out by shifting the platforms along the frame. In this case, the reducing/enlarging factor turns out to be almost continuous. To change the distance in the case of the gear transmission, the intermediate wheel is replaced with a suitable one from an existing usually limited set of wheels of different diameters. Therefore, the reducing/enlarging factor turns out to be discrete.

Analyzing mechanisms similar to the Singer-Nartov machine, we can conclude that development and building of the modern design 3D-pantograph from the point of view of the kinematic diagram complexity, the metal-working technology and the used materials was quite feasible for mechanics in the early 18th century already. By that time, all the problems related to the copying accuracy, namely: gaps in the ball and cylindrical bronze joints, backlashes in the chain/gear transmission, as well as the boom and frame rigidity (required to maintain unchanged the relative position of the pantograph elements during operation), had already been successfully solved. Therefore, it is very strange that it took so long to create a 3D-pantograph, more than 220 years!

Today, we have neither written nor material evidence confirming the existence of a construction 3D-pantograph in the 18th century. Nevertheless, taking into account the state of the art of those times, one cannot exclude the probability that such a pantograph could have been developed, built and found a limited usage in construction, but the inventor itself and his pantograph remained unknown to a wide range of experts. The fact is that the master masons in those days 
R. V. Lapshin

were in no hurry to disclose their professional secrets. Judging by how long the mystery of the polygonal masonry creation had persisted, the master masons were able to keep their secrets well.

\subsection{Who built this, when and with what funds?}

The problem with the structures based on the polygonal masonry is as follows. The official history states that the structures had existed before the arrival of Europeans in the New World in the 16th century, and the American Indians did not know neither iron tools nor a wheel and did not have draft animals at that time. From this statement, there is only one conclusion: the structures were built by some older civilization that existed in America before the Indians, meanwhile whose culture of stone working, in general, corresponded to the European construction culture of the 16-17th centuries.

The problem with this mythical older civilization is that it left behind no other material evidences of its existence, except for the perfect stone structures. As rightly noted in work 7, the highquality polygonal masonry and the structures based on it appear instantly (by historical standards) as if from nowhere, and then disappear also instantly into nowhere. There are neither previous nor subsequent noticeable development in the architecture and technology of these structures. But this may happen only when a group of professional builders comes to a certain territory for a short period, say, for 10 years, with their own tools, contrivances and construction techniques.

Transience of the events taken place in the construction industry of those years indicates the high productivity of the strange builders and their construction methods. The contradictions are instantly resolved if the authors of the structures are visiting European builders, ${ }^{24,25,26}$ and the time of erection of the structures is transferred from minus infinity to the 18th century. For delivery, moving, and rough processing of the stones, slope strengthening, and other heavy and unskilled work, of course, the local Indian people were driven together by orders of the Indian chiefs subdued/bought by the Spaniards. Thus, in a certain sense, the Peruvian megalithic complexes are the structures built by the Incas too, although not so ancient.

Any large-scale construction is always based on some strong economic foundation. It is difficult to imagine that the megalithic complexes were built for the Indians at the expense of the Spaniards. Of course, these complexes were created at the expense of the Indians and on bones of the Indians. But what could the Indians offer to the Spanish colonizers? The gold and silver that the Indians had was captured in the early years of the conquest and taken to Europe. The Peruvian land was not able to produce much cotton, sugar cane, or grain.

Since the Indians had gold and silver at the beginning of the conquest, it means they took it somewhere. Therefore, the Spaniards organized gold and silver extraction in mines and goldfields. And to make the work in the mines more fun, the aboriginal priesthood inspired the Indians with the appearance and grandiosity of the megalithic temples, which were built at the expense of part of the funds received from the extraction of the precious metals. After a few decades, the easily accessible gold and silver deposits were exhausted, and the construction of the megalithic complexes has stopped. By this time, the power of the Spaniards and the Catholic Church had increased somehow imperceptibly, and the number of the Indians was greatly reduced in some "incomprehensible" way.

Whether the miners ate poorly, or whether living in shacks did not add them a health, or whether the places of "strength" did not longer compensate for the strength taken away by the exhausting work in the mines, the history is silent. In general, the time came when a part of the abandoned religious structures of the Indians could be put in a good use without much trouble. And these structures have been put in a good use. Stone blocks and parts of the structures were used for erection of Catholic cathedrals, abbeys, palaces, villas, and city buildings. 


\section{Fabrication methods of the polygonal masonry in megalithic structures of Peru}

\section{Discussion}

Among the materials related to the topic, the work 6 should be noted. The author suggested to use a reduced gypsum model of a stone block, and transferring and scaling of a complicated surface geometry to perform with a caliper by several reference points. The gypsum model is usually required to avoid wearing of the original clay model while producing copies. This problem does not arise while fabricating blocks for the polygonal masonry. Moreover, in case of block model fabrication by a stone billet of arbitrary shape, the clay model is used just once and then thrown out (serves as a core for a new model). Thus, in order to reach the required result, possessing only a clay model of the block is quite enough.

The process of transferring of a complicated surface geometry and its scaling by few reference points using a caliper is very time-consuming and inaccurate. However, this process ceases to be time-consuming and inaccurate if we apply a pantograph instead of the caliper. Analysis shows that in most cases, first, a clay model is created by a stone billet of an arbitrary shape using a pantograph. Then, the regions are cut out in the clay model of the block for interfacing with neighboring blocks. After that, a model wall is assembled of the model blocks. After drying, the wall is disassembled, and the interface sites of the model blocks are transferred to their stone billets by means of the pantograph. Since there are no universal solutions in construction, as in any other field, the builders, besides pantograph, used other techniques based on application of the replicas.

Beside the simple front sides of the stone blocks, the described technology allows to create a polygonal masonry (facing) which face surface is a relief. The Cambodian temple complex Ang$\mathrm{kor}^{27}$ is an example, where such masonry/facing was probably used.

The knowledge accumulated in the field of mechanics and the technology level achieved by the beginning of the 18th century could quite allow to design and build the 3D-pantograph suitable for construction needs. Therefore, if we accept the method of creating polygonal masonry proposed in the article, then the construction of a number of megalithic complexes in Peru should be dated no earlier than the beginning of the 18th century.

\section{Photographs}

The photos show the polygonal masonries which can be obtained by using the methods suggested in the article. The distinctive features of these masonries are: the stone blocks are large weighing from several hundred kilograms to several tons, the blocks are mated to each other closely without a gap through complicated curved extensive surfaces.

\section{Acknowledgments}

I thank O. V. Obyedkov, Prof. I. K. Fomenko, and O. E. Lyapin for critical reading of the manuscript.

\section{Used materials}

1. O. J. Outwater, "Building the fortress of Ollantaytambo", Archaeology, vol. 12, no. 1, pp. 2632, 1959.

2. J.-P. Protzen, "Inca quarrying and stonecutting", Journal of the Society of Architectural Historians, vol. 44, no. 2, pp. 161-182, 1985.

3. J.-P. Protzen, "Inca architecture and construction at Ollantaytambo", Oxford University Press, 303 pp., New York, Oxford, 1993.

4. V. R. Lee, "The building of Sacsahuaman", Nawpa Pacha - Journal of Andean Archaeology, vol. 24, iss. 1, pp. 49-60, 1986.

5. Alexander, "Polygonal masonry: cottage technologies", YouTube, 2015 (in Russian).

6. Unraveling History, "How was the polygonal masonry made?", YouTube, 2019 (in Russian).

7. GRESAR, "Traces of somebody else's technologies", parts 1-8, YouTube, 2019-2021 (in Russian). 
R. V. Lapshin

8. Pantograph, Wikipedia.

9. M. Rogińska-Niesłuchowska, "The pantograph and its geometric transformations - a former popular tool for copying and scaling", The Journal of Polish Society for Geometry and Engineering Graphics, vol. 29, pp. 59-65, 2016.

10. Michael Keropian, "3D Pantograph Enlarging”, parts 1-7, YouTube, 2018.

11. T. Gauthier, "Photosculpture", Le Monde illustré, pp. 396-398, December 17, 1864 (in French).

12. List of earthquakes in Peru, Wikipedia.

13. Climate of Peru, Wikipedia.

14. Christoph Scheiner, Wikipedia.

15. C. Scheiner, "Pantographice seu ars delineandi res quaslibet per parallelogrammum lineare seu cavum, mechanicum, mobile", Typographia Ludouici Grignani, 108 pp., Rome, 1631 (in Latin).

16. Andrey K. Nartov, Wikipedia.

17. Turning machine for copying medals, State Hermitage Museum, St Petersburg.

18. V. V. Danilevskiy, "Nartov and his "Clear insight into machines"”, edited by A. S. Britkin, Mashgiz, 271 pp., Moscow, Leningrad, 1958 (in Russian).

19. James Watt, Wikipedia.

20. Reducing sculpture copying machine, Science Museum, London.

21. J. P. Muirhead, "The life of James Watt, with selections from his correspondence", pp. 454466, 2nd revised edition, 572 pp., John Murray, London, 1859.

22. Machine for reproducing sculpture, Science Museum, London.

23. John I. Hawkins, Wikipedia.

24. Alexander Tamanskiy, "Who and when did build the Egyptian pyramids?", YouTube, 2020 (in Russian).

25. Alexander Tamanskiy, "How were the Egyptian pyramids built?", YouTube, 2021 (in Russian).

26. Alexander Tamanskiy, "Who did build the American pyramids?", YouTube, 2021 (in Russian).

27. Angkor, Wikipedia. 